\title{
Involvement of calmodulin and calmodulin-like proteins in plant responses to abiotic stresses
}

\author{
Houqing Zeng ${ }^{1}$, Luqin $X u^{1}$, Amarjeet Singh ${ }^{2}$, Huizhong Wang ${ }^{1}$, Liqun $\mathrm{Du}^{1 *}$ and \\ B. W. Poovaiah ${ }^{2 *}$
}

${ }^{1}$ College of Life and Environmental Sciences, Hangzhou Normal University, Hangzhou, China, ${ }^{2}$ Laboratory of Molecular Plant Science, Department of Horticulture, Washington State University, Pullman, WA, USA

\section{OPEN ACCESS}

Edited by:

Girdhar Kumar Pandey,

University of Delhi South Campus,

India

Reviewed by:

Wayne Snedden

Queen's University, Canada

Tianbao Yang,

Agricultural Research Service, United

States Department of Agriculture,

USA

*Correspondence:

Liqun Du,

College of Life and Environmental

Sciences, Hangzhou Normal University, Hangzhou 310036, China liqundu@hznu.edu.cn;

B. W. Poovaiah,

Laboratory of Molecular Plant Science, Department of Horticulture, Washington State University, Pullman,

WA 99164-6414, USA

poovaiah@wsu.edu

Specialty section:

This article was submitted to

Plant Physiology,

a section of the journal

Frontiers in Plant Science

Received: 05 June 2015

Accepted: 20 July 2015

Published: 11 August 2015

Citation:

Zeng $H, X u L$, Singh $A$, Wang $H, D u L$ and Poovaiah BW (2015) Involvement

of calmodulin and calmodulin-like proteins in plant responses to abiotic

stresses.

Front. Plant Sci. 6:600 doi: 10.3389/fp/s.2015.00600
Transient changes in intracellular $\mathrm{Ca}^{2+}$ concentration have been well recognized to act as cell signals coupling various environmental stimuli to appropriate physiological responses with accuracy and specificity in plants. Calmodulin (CaM) and calmodulin-like proteins (CMLs) are major $\mathrm{Ca}^{2+}$ sensors, playing critical roles in interpreting encrypted $\mathrm{Ca}^{2+}$ signals. $\mathrm{Ca}^{2+}$-loaded CaM/CMLs interact and regulate a broad spectrum of target proteins such as channels/pumps/antiporters for various ions, transcription factors, protein kinases, protein phosphatases, metabolic enzymes, and proteins with unknown biochemical functions. Many of the target proteins of CaM/CMLs directly or indirectly regulate plant responses to environmental stresses. Basic information about stimulusinduced $\mathrm{Ca}^{2+}$ signal and overview of $\mathrm{Ca}^{2+}$ signal perception and transduction are briefly discussed in the beginning of this review. How CaM/CMLs are involved in regulating plant responses to abiotic stresses are emphasized in this review. Exciting progress has been made in the past several years, such as the elucidation of $\mathrm{Ca}^{2+} / \mathrm{CaM}$ mediated regulation of AtSR1/CAMTA3 and plant responses to chilling and freezing stresses, $\mathrm{Ca}^{2+} / \mathrm{CaM}$-mediated regulation of CAT3, MAPK8 and MKP1 in homeostasis control of reactive oxygen species signals, discovery of CaM7 as a DNA-binding transcription factor regulating plant response to light signals. However, many key questions in $\mathrm{Ca}^{2+} / \mathrm{CaM}$-mediated signaling warrant further investigation. $\mathrm{Ca}^{2+} / \mathrm{CaM}-$ mediated regulation of most of the known target proteins is presumed based on their interaction. The downstream targets of CMLs are mostly unknown, and how specificity of $\mathrm{Ca}^{2+}$ signaling could be realized through the actions of CaM/CMLs and their target proteins is largely unknown. Future breakthroughs in $\mathrm{Ca}^{2+} / \mathrm{CaM}$-mediated signaling will not only improve our understanding of how plants respond to environmental stresses, but also provide the knowledge base to improve stress-tolerance of crops.

Keywords: calcium signal, calmodulin, calmodulin-like protein, calmodulin-binding protein, signal transduction, abiotic stress

\section{Introduction}

As sessile organisms, plants encounter various types of environmental stresses, which are generally classified into biotic stresses such as insect and pathogen attacks, and abiotic stresses such as unfavorable temperature, lack of or excessive amounts of water, salinity, heavy metal toxicity, chemical toxicity, and nutrient deficiency. On the other hand, the process of industrialization 
inevitably brings many detrimental effects to the environment. Poorly controlled release of wastes from industrial processes and human life not only adds various toxic chemicals to our water and soil but also release harmful gasses into the atmosphere. Obviously, human activities are creating environmental challenges, making sustained crop production difficult. Classic agricultural technologies such as irrigation, applications of fertilizer, insecticides, fungicides, and chemical phytoprotectants have helped to improve crop yield, but the effects are limited, the costs are high and the impacts on the ecosystems and human health are undesirable and dangerous. Understanding how plants perceive and respond to various environmental stresses provides the necessary platform to create crop varieties which could fit better into the challenging environments, and has become one of the most important tasks for plant scientists around the world.

Calcium is one of the most abundant elements on earth. $\mathrm{Ca}^{2+}$ concentration outside the plasma membrane is usually at millimolar level. Since $\mathrm{Ca}^{2+}$ can form insoluble compounds with phosphate derivatives and complex with macromolecules, high levels of cytosolic $\mathrm{Ca}^{2+}$ are toxic to cells. $\mathrm{Ca}^{2+}$ concentration in the cytoplasm and nucleus is usually maintained at 50$100 \mathrm{nM}$ under resting conditions (Reddy, 2001; Yang and Poovaiah, 2003). $\mathrm{Ca}^{2+}$ gradient across the plasma membrane as well as inner membrane system are involved in cell signaling process controlled by stimulus responsive $\mathrm{Ca}^{2+}$ permeable channels, $\mathrm{Ca}^{2+}$ pumps and $\mathrm{Ca}^{2+} / \mathrm{H}^{+}$exchangers (Reddy, 2001; Kudla et al., 2010). Accumulating evidence reveals that various external stimuli such as gravity, light, cold, heat, drought, water-logging (hypoxia), salt, wind, touch, wounding, and pathogen attacks can quickly induce elevations in cytosolic $\mathrm{Ca}^{2+}$ concentration (Poovaiah and Reddy, 1993; Evans et al., 2001; Reddy, 2001; Snedden and Fromm, 2001; Zhu, 2001). Signal-induced nuclear $\mathrm{Ca}^{2+}$ changes have also been documented (Van Der Luit et al., 1999; Pauly et al., 2000), but they are not as well studied as cytosolic $\mathrm{Ca}^{2+}$ transients (Reddy et al., 2011). The excessive amount of $\mathrm{Ca}^{2+}$ in cytoplasm is quickly moved out of the cell or pumped back into the endogenous $\mathrm{Ca}^{2+}$ reservoirs such as vacuole and endoplasmic reticulum (ER) through the involvement of $\mathrm{Ca}^{2+}$ pumps and $\mathrm{Ca}^{2+} / \mathrm{H}^{+}$exchangers distributed on the plasma membrane and inner membrane system (Reddy, 2001; Kudla et al., 2010). Interestingly, the transient changes of intracellular $\mathrm{Ca}^{2+}$ concentration triggered by various stimuli differ from each other in terms of amplitude, duration, frequency, and spatial distribution inside the cell; and these stimulus-specific $\mathrm{Ca}^{2+}$ transients are named calcium signatures by Webb et al. (1996). Stimulus-specific signals are decoded by downstream effector proteins to generate specific or overlapping responses (Poovaiah et al., 2013). These effectors include $\mathrm{Ca}^{2+}$ sensor proteins which are represented by three major types in plants, namely calmodulin (CaM)/CaM-like (CML) proteins, calcium-dependent protein kinases (CDPKs) and calcineurin B like (CBL) proteins (Luan, 2009). In this review, our primary focus will be limited to CaM/CMLs and their important roles in plant abiotic stress signaling and responses.

\section{CaMs AND CMLs}

Calmodulin is a ubiquitous $\mathrm{Ca}^{2+}$-binding protein which exists in all eukaryotes (Snedden and Fromm, 1998; Yang and Poovaiah, 2003; McCormack et al., 2005; Kim et al., 2009; Du et al., 2011). It is a small acidic protein composed of two pairs of EF-hands located at both the $\mathrm{N}$ - and C-terminus. In Arabidopsis, seven genes encode four CaM isoforms (CaM1/4; CaM2/3/5; CaM6; CaM7), which differ only in one to five amino acid residues (McCormack and Braam, 2003; McCormack et al., 2005). It has been reported that different $\mathrm{CaM}$ isoforms differ in binding and regulating downstream effectors (Lee et al., 2000; Yoo et al., 2005). The slight differences in their structural features may have considerable impacts on their binding to targets (Yamniuk and Vogel, 2005).

In addition to canonical CaM, there are 50 genes coding for CaM-like proteins in the Arabidopsis genome which are made of varying number of EF hands and share at least $16 \%$ of overall sequence identity with canonical CaM (McCormack and Braam, 2003). Similarly, five CaM and 32 CML genes, respectively are reported in the rice genome (Boonburapong and Buaboocha, 2007). Despite having four EF hands, most CMLs show low (less than 50\%) overall similarity to CaMs (McCormack and Braam, 2003; Boonburapong and Buaboocha, 2007; Perochon et al., 2011). Several Arabidopsis CMLs, including CML37, 38, 39 , and 42 displayed an electrophoretic mobility shift in the presence of $\mathrm{Ca}^{2+}$, indicating that, like CaMs, CMLs also act as $\mathrm{Ca}^{2+}$ sensors (Vanderbeld and Snedden, 2007; Dobney et al., 2009). Besides EF-hands, CaMs and CMLs do not carry any known functional domain, and hence usually have no enzymatic or biochemical functions. So far the only exception is CaM7 from Arabidopsis which was reported to specifically bind Z-/Gbox in a $\mathrm{Ca}^{2+}$-dependent manner and act as a transcription factor to regulate light-responsive gene expression and light morphogenesis (Kushwaha et al., 2008). Therefore, identifying CaM/CML targets and understanding the impacts of CaM/CMLbinding on their functional behaviors are the major challenges in deciphering the functional significance of CaM/CMLs at molecular, biochemical, and physiological levels.

It is well-documented that $\mathrm{Ca}^{2+}$-binding-induced conformational changes in CaMs and CMLs usually increase their binding affinity to downstream targets through hydrophobic and electrostatic interactions (Snedden and Fromm, 1998; Hoeflich and Ikura, 2002). A stretch of 16-35 amino acids in the target proteins called CaM-binding domain (CaMBD) is usually necessary and sufficient for its interaction with CaM (Rhoads and Friedberg, 1997; Hoeflich and Ikura, 2002). In some cases, CaM interacts with its target proteins in a $\mathrm{Ca}^{2+}$-independent manner, and this kind of interaction requires that the target proteins carry an IQ motif, a stretch of amino acids fitting a conserved pattern of IQXXX(R/K)GXXXR where I could be replaced with "FLV" and " $X$ " represents any amino acid residue (Hoeflich and Ikura, 2002; Yamniuk and Vogel, 2004). CMLs could follow similar models to interact with their targets; however, this assumption requires experimental verification. Usually, CaMBDs are not conserved in their primary structure, however, most of the $\mathrm{Ca}^{2+}$-dependent CaMBD peptides share a conserved secondary 
structure, a basic amphipathic helix with hydrophobic residues arranged on one side and positively charged residues arranged on the other side (Snedden and Fromm, 2001; Du and Poovaiah, 2004). Hence, most CaM and CML target proteins have to be identified empirically.

\section{Targets of CaMs and CMLs}

As mentioned above, the interactions between CaM/CMLs and target proteins are usually $\mathrm{Ca}^{2+}$-dependent; regular strategies used for detection of protein-protein interaction including yeast-two-hybrid and coimmunoprecipitation are not effective and fruitful in identifying CaM/CML-binding proteins. The majority of the CaM-binding proteins (CBPs) from plants were identified by screening cDNA expression libraries with labeled CaM as probes (usually ${ }^{35}$ S-labled; Fromm and Chua, 1992; Reddy et al., 1993; Yang and Poovaiah, 2000b). Another effective approach to identify CBPs is utilizing protein microarray (Popescu et al., 2007); however, false positive identification is still a major concern and making protein chips with adequate coverage is currently a challenge. Accumulated results indicated that CaM bind to a variety of CBPs in plants, which include kinases, phosphatases, transcription factors, receptors, metabolic enzymes, ion channels and pumps, and cytoskeletal proteins (Snedden and Fromm, 2001; Bouche et al., 2005; Kim et al., 2009; Du et al., 2011; Reddy et al., 2011). Hence, it is reasonable to conclude that, in most cases, CaMs and CMLs act as multifunctional regulatory proteins, and their functional significance is materialized through the actions of their downstream target proteins. CBPs with well-defined CaMbinding domain, CaM-binding property and involved in plant responses to abiotic stresses are listed in Table $\mathbf{1 .}$

\section{$\mathrm{Ca}^{2+} / \mathrm{CAM}$ and ROS Crosstalk in Plant Response to Stresses}

Reactive oxygen species (ROS) such as hydrogen peroxide $\left(\mathrm{H}_{2} \mathrm{O}_{2}\right)$, superoxide anion $\left(\mathrm{O}_{2}^{-}\right)$, and hydroxyl radical $(\cdot \mathrm{OH})$ are usually produced in various physiological processes and serve as a class of second messengers (Van Breusegem et al., 2001; Apel and Hirt, 2004). While controlled production of ROS is essential to signal appropriate actions to protect plants from various environmental stresses, excessive accumulation of ROS causes damages to plant cells. Oxidative stress is defined as disruption of the cellular redox balance, which could be triggered by a wide range of biotic and abiotic stimuli (Rentel and Knight, 2004). Because of its long half-life and excellent permeability, $\mathrm{H}_{2} \mathrm{O}_{2}$ is broadly accepted as the major form of ROS in plant cells. It is well known that $\mathrm{H}_{2} \mathrm{O}_{2}$ can trigger increases in cytosolic $\mathrm{Ca}^{2+}$ by activating the $\mathrm{Ca}^{2+}$-permeable channels (Price et al., 1994; Rentel and Knight, 2004). On the other hand, $\mathrm{H}_{2} \mathrm{O}_{2}$ production during oxidative burst is also dependent on continuous $\mathrm{Ca}^{2+}$ influx, which activates not only the NADPH oxidase, an EFhand containing enzyme on the plasma membrane (Xing et al., 1997), but also the CaM-binding NAD kinase (NADK), which supplies NADP cofactor for ROS production through NADPH oxidase (Harding et al., 1997; Karita et al., 2004; Turner et al., 2004).

In addition, early studies from heat-stressed maize seedling suggested that ROS homeostasis and the entire antioxidant system including catalase, superoxide dismutase (SOD) and ascorbate peroxidase, could be regulated by $\mathrm{Ca}^{2+}$ influx and intracellular CaM (Gong et al., 1997a). Later plant catalases, a class of $\mathrm{H}_{2} \mathrm{O}_{2}$ scavenger enzymes catalyzing its degradation to water and oxygen was found to bind $\mathrm{CaM}$ in a $\mathrm{Ca}^{2+}$. dependent manner (Yang and Poovaiah, 2002b). The activity of the Arabidopsis CAT3 is stimulated by $\mathrm{Ca}^{2+} / \mathrm{CaM}$ rather than $\mathrm{Ca}^{2+}$ or CaM alone, but catalases from other organisms such as Aspergillus niger, human and bovine, do not interact with CaM (Yang and Poovaiah, 2002b). A peroxidase from Euphorbia latex, was also reported to be a CBP activated by $\mathrm{Ca}^{2+} / \mathrm{CaM}$ (Medda et al., 2003; Mura et al., 2005). Evidence also suggests that another class of ROS-scavenging enzyme SOD could be regulated by CaM in maize, although the specific SOD gene has not been cloned (Gong and $\mathrm{Li}, 1995$ ). The critical role of $\mathrm{Ca}^{2+} / \mathrm{CaM}$ in balancing ROS actions was further supported by the observation that the oxidative damage caused by heat stress in Arabidopsis seedlings is exacerbated by pretreatment with CaM inhibitors (Larkindale and Knight, 2002).

In addition to these direct regulations on ROS homeostasis, $\mathrm{Ca}^{2+} / \mathrm{CaM}$-mediated signaling is also well known to regulate ROS-related signal transduction at various stages. Maize CAP1 encoding a novel form of CaM-regulated $\mathrm{Ca}^{2+}$-ATPase was shown to be induced only during early anoxia, indicating its possible role in oxygen-deprived maize cells (Subbaiah and Sachs, 2000). CaM may also participate indirectly in regulating ROS content through the CaM-regulated $\lambda$-aminobutyrate (GABA) synthesis and the GABA shunt metabolic pathway (Bouche et al., 2003). Recently, it was demonstrated that ZmCCaMK and OsDMI3 (also called OsCCaMK) from maize (Zea mays) and rice (Oryza sativa), respectively, play a critical role in ABAinduced antioxidant actions (Ma et al., 2012; Shi et al., 2012), suggesting a role for CCaMK in plant oxidative stress response. Arabidopsis MPK8 was found to be activated by $\mathrm{CaM}$ and activated MPK8 suppresses wound-induced ROS accumulation via transcriptional control of $R b o h D$ expression, revealing a novel mechanism for CaM-mediated signaling to fine-tune ROS homeostasis under wounding stress (Takahashi et al., 2011). Interestingly, some genes encoding CaM-binding transcription factors (CAMTAs) and co-factor (AtBTs) are responsive to $\mathrm{H}_{2} \mathrm{O}_{2}$, suggesting that $\mathrm{CaM}$-mediated signaling could directly regulate gene expression in plant responses to oxidative cues (Yang and Poovaiah, 2002a; Du and Poovaiah, 2004; Wang et al., 2015).

\section{CaM/CML-Mediated Regulation of Abiotic Stress Signaling}

\section{Heat Stress}

Prolonged high temperature is usually lethal to all organisms; fluctuations in temperature above optimal level, usually called heat shock (HS), impose major stress affecting plant growth and 
TABLE 1 | Involvement of calmodulins (CaMs), CaM-like proteins (CMLs), and CaM-binding proteins (CBPs) in plant responses to diverse abiotic stresses.

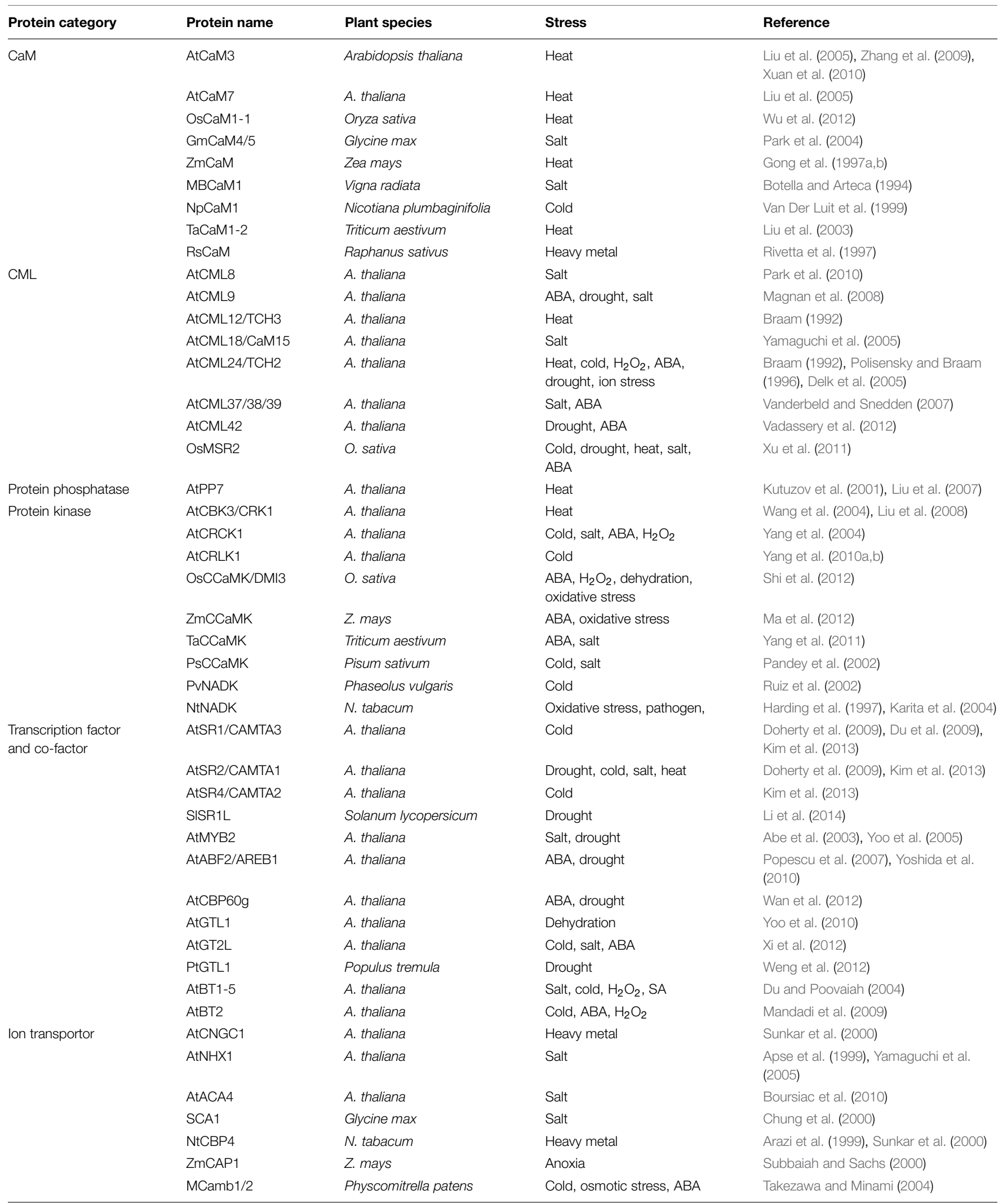


TABLE 1 | Continued

\begin{tabular}{|c|c|c|c|c|}
\hline Protein category & Protein name & Plant species & Stress & Reference \\
\hline \multirow[t]{5}{*}{ Metabolic enzyme } & AtCAT3 & A. thaliana & Oxidative stress & Yang and Poovaiah (2002b) \\
\hline & ZmSOD & Z. mays & Oxidative stress & Gong et al. (1997a) \\
\hline & OsGAD & O. sativa & Anoxia & Aurisano et al. (1995) \\
\hline & ELP/EcPeroxidase & Euphorbia characias & $\mathrm{H}_{2} \mathrm{O}_{2}$ & Medda et al. (2003), Mura et al. (2005) \\
\hline & BiGly-I & Brassica juncea & $\begin{array}{l}\text { Salt, dehydration, heavy } \\
\text { metal }\end{array}$ & $\begin{array}{l}\text { Deswal and Sopory (1999), Veena et al. } \\
\text { (1999), Singla-Pareek et al. (2003) }\end{array}$ \\
\hline \multirow[t]{5}{*}{ Unclassified } & AtCaMBP25 & A. thaliana & Osmotic stress & Perruc et al. (2004) \\
\hline & AtIQM1 & A. thaliana & ABA, dehydration & Zhou et al. (2012) \\
\hline & $\mathrm{ZmHsp70}$ & Z. mays & Heat & Sun et al. (2000) \\
\hline & DgHsp70 & Orchardgrass & Heat & Cha et al. (2012) \\
\hline & pTCB48 & N. tabacum & Heat & Lu et al. (1995) \\
\hline
\end{tabular}

productivity. Almost all organisms including plants synthesize HS proteins (HSPs), a class of chaperons to assure normal function of various client proteins under adversely high temperature conditions. It was observed long ago that HS induced a quick and strong increase in cytosolic $\mathrm{Ca}^{2+}$ in tobacco (Gong et al., 1998). Expression of CaM in the maize coleoptiles was found to be remarkably induced during $\mathrm{HS}$ and was affected by $\mathrm{Ca}^{2+}$ level, suggesting that $\mathrm{Ca}^{2+}$ and CaM may be involved in the acquisition of HS-induced thermotolerance (Gong et al., 1997b). Liu et al. (2003) observed an increase in intracellular $\mathrm{Ca}^{2+}$ within one min after wheat was subjected to $37^{\circ} \mathrm{C} \mathrm{HS}$. Expression of CaM mRNA and protein was both induced by HS in the presence of $\mathrm{Ca}^{2+}$, and expression of HSP26 and HSP70 was stimulated by exogenous application of $\mathrm{Ca}^{2+}$. HSinduced expression of CaM was $10 \mathrm{~min}$ earlier than that of $H S P$ s, and both were suspended by pharmacological reagents which interfere with $\mathrm{Ca}^{2+}$ signaling. These results indicate that $\mathrm{Ca}^{2+}$ and $\mathrm{CaM}$ are directly involved in $\mathrm{HS}$ signaling (Liu et al., 2003). The $\mathrm{Ca}^{2+} / \mathrm{CaM}$ signaling system was also proposed to be involved in the induction of HSP genes in Arabidopsis (Liu et al., 2005). Using molecular and genetic tools, Zhang et al. (2009) found that Arabidopsis AtCaM3 was involved in the $\mathrm{Ca}^{2+} / \mathrm{CaM}$-mediated $\mathrm{HS}$ signal transduction pathway. atcam 3 loss-of-function mutant showed a pronounced decrease in thermotolerance after $50 \mathrm{~min}$ of incubation at $45^{\circ} \mathrm{C}$. The compromised thermotolerance of atcam 3 mutant could be rescued by functional complementation with $35 \mathrm{~S}$ promoter driven AtCaM3, and overexpression of AtCaM3 in wild-type (WT) background increased thermotolerance of the transgenic plants. Furthermore, the DNA-binding activity of HS transcription factors and the expression of tested HS genes at both mRNA and protein levels were shown to be down-regulated in atcam 3 null mutant and up-regulated in its overexpressing lines upon HS treatment (Zhang et al., 2009). A role for CaM in HS signaling was also demonstrated in rice (Wu and Jinn, 2012; Wu et al., 2012). HS was reported to induce biphasic cytosolic $\mathrm{Ca}^{2+}$ transients, and this signature feature was found to be reflected in the HS-induced expression of OsCaM1-1. OsCaM1-1 was observed to localize to the nucleus and overexpression of OsCaM1-1 in Arabidopsis resulted in enhanced thermotolerance which coincided with elevated expression of HS-responsive AtCBK3, AtPP7, AtHSF, and AtHSP at a non-inducing temperature. Nitric oxide (NO) level in plants was found to be elevated by high temperatures (Gould et al., 2003), and exogenous application of NO donor provides effective protection to plants under heat stress (Uchida et al., 2002; Song et al., 2006). However, for a long time it was unknown how NO is involved in protecting plants from damage by HS. Recently, Arabidopsis CaM3 was reported to act as a downstream factor of NO in activation of HS transcription factors, accumulation of HSPs and establishment of thermotolerance (Xuan et al., 2010).

Calmodulin-binding proteins have also been shown to play a crucial role in mediating plant responses to heat stress. pTCB48 encoding a CBP was isolated by screening a cDNA expression library constructed from tobacco cell cultures subjected to HS, and its expression was strongly induced by HS treatment, suggesting a role in HS response (Lu et al., 1995). Maize cytosolic Hsp70 was identified to bind $\mathrm{CaM}$ in the presence of $\mathrm{Ca}^{2+}$ and could inhibit the activity of CaM-dependent NADK in a concentration-dependent manner, but its possible function in HS response has not been elucidated (Sun et al., 2000). Recently, DgHsp70, a homolog of cytosolic Hsp70 from orchardgrass (Dactylis glomerata) was also found to bind AtCaM2 in the presence of $\mathrm{Ca}^{2+}$, and the binding of $\mathrm{Ca}^{2+} / \mathrm{CaM}$ decreased the ATPase and foldase activities of this chaperon protein (Cha et al., 2012). PP7 is a ser/thr protein phosphatase which interacts with $\mathrm{CaM}$ in a $\mathrm{Ca}^{2+}$-dependent manner (Kutuzov et al., 2001). Arabidopsis AtPP7 was induced by HS and its knockout mutant is impaired in thermotolerance, while the overexpression of AtPP7 results in increased thermotolerance and increased expression of AtHSP70 and AtHSP101 following HS treatment (Liu et al., 2007). Interestingly, AtPP7 was also found to interact with HS transcription factor AtHSF1 implying that AtPP7 could also regulate the expression of HSP genes via AtHSF1 (Liu et al., 2007). However, the mechanistic detail by which AtPP7 dephosphorylates and regulates downstream substrates such as AtHSF1 is not clear. Arabidopsis AtCRK1 (CDPK-related protein kinase 1, also called AtCBK3) was identified as a $\mathrm{Ca}^{2+}$-dependent CBP (Wang et al., 2004). Liu et al. (2008) found that AtCBK3 activates HSFs which further regulate HS gene expression by binding to HS elements. 


\section{Cold Stress}

$\mathrm{Ca}^{2+}$ has been recognized as a vital second messenger coupling cold stress to specific plant responses (Knight et al., 1991; Dodd et al., 2010). Researchers found that cold shock and wind initiate $\mathrm{Ca}^{2+}$ transients in both cytosol and nucleus in transgenic tobacco (Nicotiana plumbaginifolia) seedlings expressing aequorin, and the expression of NpCaM-1 is induced by both cold shock and wind but mediated by distinct $\mathrm{Ca}^{2+}$ signaling pathways operating predominantly in the cytoplasm or in the nucleus (Van Der Luit et al., 1999). Transgenic Arabidopsis plants overexpressing CaM3 showed decreased levels of COR (cold regulated) transcripts suggesting CaM may function as a negative regulator of cold-induced gene expression (Townley and Knight, 2002). Genes encoding CMLs, such as AtCML24/TCH2 and OsMSR2 (O. sativa Multi-Stress-Responsive gene2, a novel CML gene), were also found to be induced by cold treatment and thus, likely participate in transducing cold-induced $\mathrm{Ca}^{2+}$ signals (Polisensky and Braam, 1996; Delk et al., 2005; Xu et al., 2011).

In addition, as downstream effectors of $\mathrm{Ca}^{2+} / \mathrm{CaM}$-mediated signaling, CBPs are also known to be involved in plant responses to cold stress. $\mathrm{Ca}^{2+} / \mathrm{CaM}$-regulated receptor-like kinase CRLK1, which is mainly localized in the plasma membrane, was found to be involved in cold tolerance (Yang et al., 2010b). CRLK1 carries two CaM-binding sites in both $\mathrm{N}$ - and C-termini with affinities for $\mathrm{Ca}^{2+} / \mathrm{CaM}$ of 25 and $160 \mathrm{nM}$, respectively (Yang et al., 2010b). crlk1 knockout mutant plants grow and behave like WT plants under regular conditions, but are more sensitive to chilling and freezing treatments than WT plants (Yang et al., 2010b). In addition, cold response genes such as $C B F 1, R D 29 A, C O R 15 a$, and KIN1 showed delayed responses to cold in $c r l k 1$, suggesting a positive role for CRLK1 in regulating cold tolerance. MEKK1, which is a member of the MAP kinase kinase kinase family, was shown to interact with CRLK1 both in vitro and in planta (Yang et al., 2010a). Knockout mutation of CRLK1 abolished the cold-triggered MAP kinase activities, and altered cold-induced expression of genes involved in MAP kinase signaling (Yang et al., 2010a). Therefore, $\mathrm{Ca}^{2+} / \mathrm{CaM}$-regulated CRLK1 may modulate cold acclimation through MAP kinase cascade in plants. Other CaM-binding kinases are also suggested to be involved in cold acclimation. The expression of PsCCaMK in pea (Pisum sativa) roots was found to be up-regulated by low temperature or salinity stress (Pandey et al., 2002), and the activity of the $\mathrm{Ca}^{2+} / \mathrm{CaM}-$ dependent NADK was found to be increased by cold shock (Ruiz et al., 2002).

AtSRs/CAMTAs belong to one of the best characterized classes of CaM-binding transcription factors in plants and animals (Reddy et al., 2000; Yang and Poovaiah, 2000a, 2002a; Bouche et al., 2002; Choi et al., 2005; Du et al., 2011; Reddy et al., 2011). In an attempt to understand transcriptional control of CBF2 (a critical regulator of cold acclimation), Doherty et al. (2009) compared the promoter sequence of three CBFs and found seven conserved DNA motifs CM1 to 7 in their promoters. CM2 is a typical AtSR1/CAMTA3 recognition motif, and importantly, the expression of $C B F 2$ was found to be positively regulated by AtSR1/CAMTA3. Although camta3 knockout mutant had no phenotypic change under cold stress, camta1/camta3 double mutant was found to have reduced freezing tolerance (Doherty et al., 2009). Recently, AtCAMTA1, AtCAMTA2, and AtCAMTA3 were shown to participate in cold tolerance by cooperatively inducing $C B F$ genes and repressing SA biosynthesis (Kim et al., 2013). These results filled a longstanding knowledge gap between cold induced $\mathrm{Ca}^{2+}$ transients and cold-regulated gene expression.

Several Arabidopsis MADS box transcription factors were identified as putative CBPs by a high throughput proteomics approach (Popescu et al., 2007). Expression of some of these MADS box genes, including AGL3, AGL8, AGL15, and AGL32, was reported to be suppressed by cold stress (Hannah et al., 2005), implying a role for $\mathrm{Ca}^{2+}$ signal to regulate cold responses through the MADS proteins, however, whether and how $\mathrm{Ca}^{2+} / \mathrm{CaM}$ regulates MADS box transcription factors remain to be addressed. The expression of $C B F 2$ is down-regulated in transgenic Arabidopsis plants constitutively expressing AGL15, in comparison to WT plants (Hill et al., 2008). GT factors are plantspecific transcription factors sharing a conserved trihelix DNAbinding domain that specifically interacts with GT cis-elements (Wang et al., 2014). Recently, AtGT2L, a classic member of the GT-2 subfamily, was identified to encode a $\mathrm{Ca}^{2+}$-dependent $\mathrm{CBP}$ and it is responsive to cold, salt and ABA treatments (Xi et al., 2012). Furthermore, overexpression of $A t G T 2 L$ resulted in elevated expression levels of cold- and salt-specific marker genes $R D 29 A$ and ERD10, both in basal and chilling- or salttreated conditions. These results indicated that $\mathrm{Ca}^{2+} / \mathrm{CaM}-$ binding AtGT2L is involved in plant responses to cold and salt stresses (Xi et al., 2012).

\section{Salt and Drought Stress}

High salinity and drought are the major environmental stresses frequently experienced by plants, and both impose osmotic stress on plant cells. Osmotic stress induces a series of responses at the molecular and cellular levels and a primary event is an increase in the cytosolic $\mathrm{Ca}^{2+}$ concentration and subsequent transduction of $\mathrm{Ca}^{2+}$ signals that promotes appropriate cellular responses in an effort to mitigate potential damages (Xiong and Zhu, 2002; Zhu, 2002). In addition to the well documented salt-overly-sensitive (SOS) pathway (Chinnusamy et al., 2004; Mahajan et al., 2008), CaM-mediated signaling is also actively involved in plant response to osmotic stress (Bouche et al., 2005). Overexpression of a salt-induced CaM gene from soybean, GmCaM4, in Arabidopsis confers salt stress tolerance through the up-regulation of DNA-binding activity of a MYB transcription factor MYB2. Interestingly, MYB2 was also reported to interact with $\mathrm{CaM}$ in a $\mathrm{Ca}^{2+}$-dependent manner and regulate salt and dehydration responsive genes (Abe et al., 2003; Yoo et al., 2005). AtCML8, an ortholog of GmCaM4, was also found to be induced by salt treatment (Park et al., 2010). Another similar CML protein AtCML9 was found to be involved in osmotic stress tolerance through ABA-mediated pathways (Magnan et al., 2008). AtCML9 was readily induced by abiotic stress and ABA; knock-out mutant atcml9 showed a hypersensitive response to $\mathrm{ABA}$ during seed germination and seedling growth stages, and exhibited enhanced tolerance to salt and dehydration stresses. Furthermore, expression of several stress and ABA-responsive 
genes including $R A B 18, R D 29 A$, and $R D 20$ was altered in atcml9. The rice CML gene OsMSR2 was also suggested to be involved in ABA-mediated salt and drought tolerance (Xu et al., 2011). As the most abundant vacuolar $\mathrm{Na}^{+}$-proton exchanger in Arabidopsis, $\mathrm{Na}^{+} / \mathrm{H}^{+}$exchanger 1 (AtNHX1) regulates various cellular activities such as maintaining $\mathrm{pH}$, ion homeostasis, and protein trafficking. Yamaguchi et al. (2005) found that AtCaM15 (also called AtCML18) is localized in the vacuolar lumen and interacts with the C-terminus of AtNHX1. The interaction between AtCaM15 and AtNHX1 is affected by both $\mathrm{Ca}^{2+}$ and $\mathrm{pH}$, and the binding of AtCaM15 to AtNHX1 alters the $\mathrm{Na}^{+} / \mathrm{K}^{+}$ selectivity of the exchanger by decreasing its $\mathrm{Na}^{+} / \mathrm{H}^{+}$exchange speed. The interaction between AtCaM15 and AtNHX1 suggests the presence of $\mathrm{Ca}^{2+}-\mathrm{pH}$-dependent signaling components in the vacuole, which are involved in mediating plant responses to salt stress. In addition to the above mentioned CaM/CMLs, CML37, CML38, and CML39 are also responsive to various stimuli, including salt, drought, and ABA (Vanderbeld and Snedden, 2007), but whether they are also involved in osmotic stress tolerance remains to be identified.

A few CaMBPs are involved in the signaling pathways triggered by salt, drought or osmotic stresses. Wheat (Triticum aestivum) TaCCaMK was down-regulated by ABA, salt and PEG treatments, and overexpression of TaCCaMK reduces ABA sensitivity of Arabidopsis, indicating that TaCCaMK is a negative regulator of ABA-mediated signaling (Yang et al., 2011). Arabidopsis AtACA4 encoding a CaM-regulated $\mathrm{Ca}^{2+}$ ATPase was found to be localized to small vacuoles, which is similar to PMC1, the yeast vacuolar $\mathrm{Ca}^{2+}$-ATPase, and AtACA4 confers tolerance against osmotic stresses imposed by high $\mathrm{NaCl}$, $\mathrm{KCl}$, and mannitol, when expressed in the yeast $\mathrm{K} 616$ strain lacking $\mathrm{Ca}^{2+}$ transporter PMC1 (Geisler et al., 2000). A CaMregulated $\mathrm{Ca}^{2+}$-ATPase gene from soybean, SCA1, was found to be induced by salt stress (Chung et al., 2000). Methylglyoxal (MG), a byproduct of carbohydrate and lipid metabolism and a potent mutagenic chemical known to arrest growth, reacts with DNA and protein and increases sister chromatid exchange; and glyoxalase enzymes, including glyoxalase I (glyI) and glyoxalase II (gly-II), catalyze the detoxification of MG with the involvement of glutathione (GSH; Thornalley, 1990). Glyoxalase I from Brassica juncea (BjGly-I) was reported to be a $\mathrm{Ca}^{2+} / \mathrm{CBP}$, and its enzymatic function is significantly stimulated by $\mathrm{Ca}^{2+} / \mathrm{CaM}$ binding (Deswal and Sopory, 1999). The expression of BjGly-I is induced by salt, dehydration and heavy metal stresses; ectopic expression of BjGly-I in tobacco conferred remarkable tolerance to exogenous $M G$ and high salt stress (Veena et al., 1999). AtCaMBP25 was identified to be a CaM-binding nuclear protein and is induced by dehydration, low temperature or high salinity. Overexpression of AtCaMBP25 compromised the tolerance of transgenic plants to osmotic stress, and silencing AtCaMBP25 via antisense approach increased plant tolerance to osmotic stress. These results suggested that AtCaMBP25 functions as a negative regulator in plant tolerance to osmotic stress, revealing a connection coupling $\mathrm{Ca}^{2+}$ signals to plant responses to osmotic stresses (Perruc et al., 2004).

$\mathrm{Ca}^{2+} / \mathrm{CaM}$-regulated transcription factors are also involved in plant response to salt and drought stresses. A few CAMTA genes from Arabidopsis and soybean are up-regulated by salt and dehydration treatments (Yang and Poovaiah, 2002a; Galon et al., 2010; Wang et al., 2015). Arabidopsis CAMTA1 is involved in drought stress response (Pandey et al., 2013). Knockout mutant camtal was shown to be more sensitive to drought stress, and expression of many drought responsive genes was affected in this mutant. Similar to AtCAMTA1, tomato CAMTA homolog SISR1L was also positively involved in drought stress tolerance (Li et al., 2014). In addition to regulating salicylic acid (SA)-induced defense response and systemic acquired resistance (Wang et al., 2009; Zhang et al., 2010), AtCBP60g, a CaM-binding transcription factor from Arabidopsis was found to positively regulate drought stress response (Wan et al., 2012). Transgenic plants overexpressing CBP60g displayed hypersensitivity to ABA and enhanced tolerance to drought stress. AtGTL1 (GT-2 LIKE1), a CaM-binding member of the GTL transcription factor family, was found to be a negative regulator of drought tolerance (Yoo et al., 2010). AtGTL1 expression was down-regulated by dehydration stress, and loss-of-function mutant gtl1 showed better survival under drought stress by reducing transpiration, due to lower stomata density on the abaxial surface and higher expression of SDD1, which is a negative regulator of stomatal development and is repressed by AtGTL1 (Yoo et al., 2010). Similarly, PtaGTL1 identified from Populus tremula $\times$ P. alba could bind to CaM and regulate water use efficiency and drought tolerance (Weng et al., 2012). Another transcription factor AtABF2/AREB1, which was identified as CBP through protein microarray analysis (Popescu et al., 2007), was also found to be up-regulated by $\mathrm{ABA}$, dehydration, and salinity stresses (Yoshida et al., 2010). Single and multiple mutants of ABF2, 3, and 4 showed varying degrees of reduced survival rate under drought conditions, implying functional redundancy among these three $\mathrm{ABFs}$ and $\mathrm{Ca}^{2+} / \mathrm{CaM}$ could regulate drought tolerance through ABF2/AREB1 (Yoshida et al., 2010).

\section{Heavy Metal Stress}

Elevated concentration of both essential (e.g., $\mathrm{Cu}$ and $\mathrm{Zn}$ ) and non-essential (e.g., $\mathrm{Cd}, \mathrm{Hg}, \mathrm{Pb}$, and $\mathrm{Ni}$ ) heavy metals in the soil can cause toxicity and inhibit plant growth. It was reported that $\mathrm{Ca}^{2+} / \mathrm{CaM}$ is involved in radish (Raphanus sativus L.) responses to $\mathrm{Cd}^{2+}$ toxicity during the early phases of seed germination (Rivetta et al., 1997). $\mathrm{Ca}^{2+}$ added in the medium could partially reverse the $\mathrm{Cd}^{2+}$-induced growth inhibition of the germinating embryo, and this coincides with decreased $\mathrm{Cd}^{2+}$ uptake. An equilibrium dialysis study revealed that $\mathrm{Cd}^{2+}$ compete with $\mathrm{Ca}^{2+}$ for CaM-binding, hence $\mathrm{Cd}^{2+}$ could significantly reduce the binding of $\mathrm{Ca}^{2+} / \mathrm{CaM}$ to its target proteins. Apparently, supplementation of $\mathrm{Ca}^{2+}$ in the medium counteracts the toxicity of $\mathrm{Cd}^{2+}$ by restoring the $\mathrm{Ca}^{2+}$-dependent interaction between $\mathrm{CaM}$ and its targets during the radish seed germination. A tobacco ( $N$. tabacum) cyclic nucleotide gated ion channel (CNGC) called NtCBP4 was identified to be a CBP through protein-protein interaction-based library screening, and shown to be localized to plasma membrane. Transgenic tobacco plants with elevated expression of NtCBP4 displayed tolerance to $\mathrm{Ni}^{2+}$ and hypersensitivity to $\mathrm{Pb}^{2+}$, and consistently showed decreased $\mathrm{Ni}^{2+}$ and increased $\mathrm{Pb}^{2+}$ accumulation, suggesting 
that NtCBP4 is involved in heavy metal uptake across the plant plasma membrane (Arazi et al., 1999). However, transgenic plants expressing a truncated version of NtCBP4 lacking the C-terminal stretch covering the CaMBD and part of the putative cyclic nucleotide-binding domain showed improved tolerance to $\mathrm{Pb}^{2+}$ and lower accumulation of $\mathrm{Pb}^{2+}$, and loss-of-function mutation of AtCNGC1, a homolog of NtCBP4 in Arabidopsis, also resulted in $\mathrm{Pb}^{2+}$ tolerance. These results suggested that CaM-binding is required for the normal function of both AtCNGC1 and NtCBP4 for the transport of heavy metals (Sunkar et al., 2000).

\section{Conclusion and Perspectives}

$\mathrm{Ca}^{2+}$ is a critical second messenger coupling diverse stimuli to various physiological responses in plants. CaM, as well as $\mathrm{CML}$, is one of the most extensively studied $\mathrm{Ca}^{2+}$ sensors, which mediate interpretation of $\mathrm{Ca}^{2+}$ signals in all aspects of plant life, especially in responses to environmental stresses, through interaction with and regulation of various downstream target proteins. Figure 1 depicts an overview of generation and interpretation of $\mathrm{Ca}^{2+}$ signals which are regulated by CaM/CMLs during plant responses to abiotic stresses. One of the most actively regulated class of target proteins are calcium permeable channels, pumps, and antiporters which are actively involved in the generation of intracellular $\mathrm{Ca}^{2+}$ transients. This indicates that the preciseness and accuracy of $\mathrm{Ca}^{2+}$ signal itself is closely monitored by CaM-mediated regulation. Although more than 50 proteins from different plant species have been identified as CBPs with well-defined CaM-binding properties (Table 1), the CaM-mediated regulations of these target proteins are frequently presumptive including SAURs, PCBP, AtBTs, and WRKYIIds (Yang and Poovaiah, 2000a; Reddy et al., 2002; Du and Poovaiah, 2004; Park et al., 2005). Only a few cases of CaM-mediated regulation in planta are supported with empirical evidences, such as GAD, CCaMK, AtCAT3, MLO, DWF1, AtSRs/CaMTAs, CRLK1, and CBP60g (Snedden et al., 1996; Kim et al., 2002; Yang and Poovaiah, 2002b; Du and Poovaiah, 2005; Gleason et al., 2006; Tirichine et al., 2006; Du et al., 2009; Wang et al., 2009; Yang et al., 2010b). Hence, more emphasis should be placed on studying the CaM-mediated regulation of target proteins to further improve our understanding of CaM-mediated signaling. Currently, most of the CBPs are targets of canonic CaMs which count for only $10 \%$ of the CaM/CML family. The targets of most of the CMLs are not reported yet, let alone the CML-mediated regulation of downstream targets and associated signal transduction. Identification of novel target proteins of

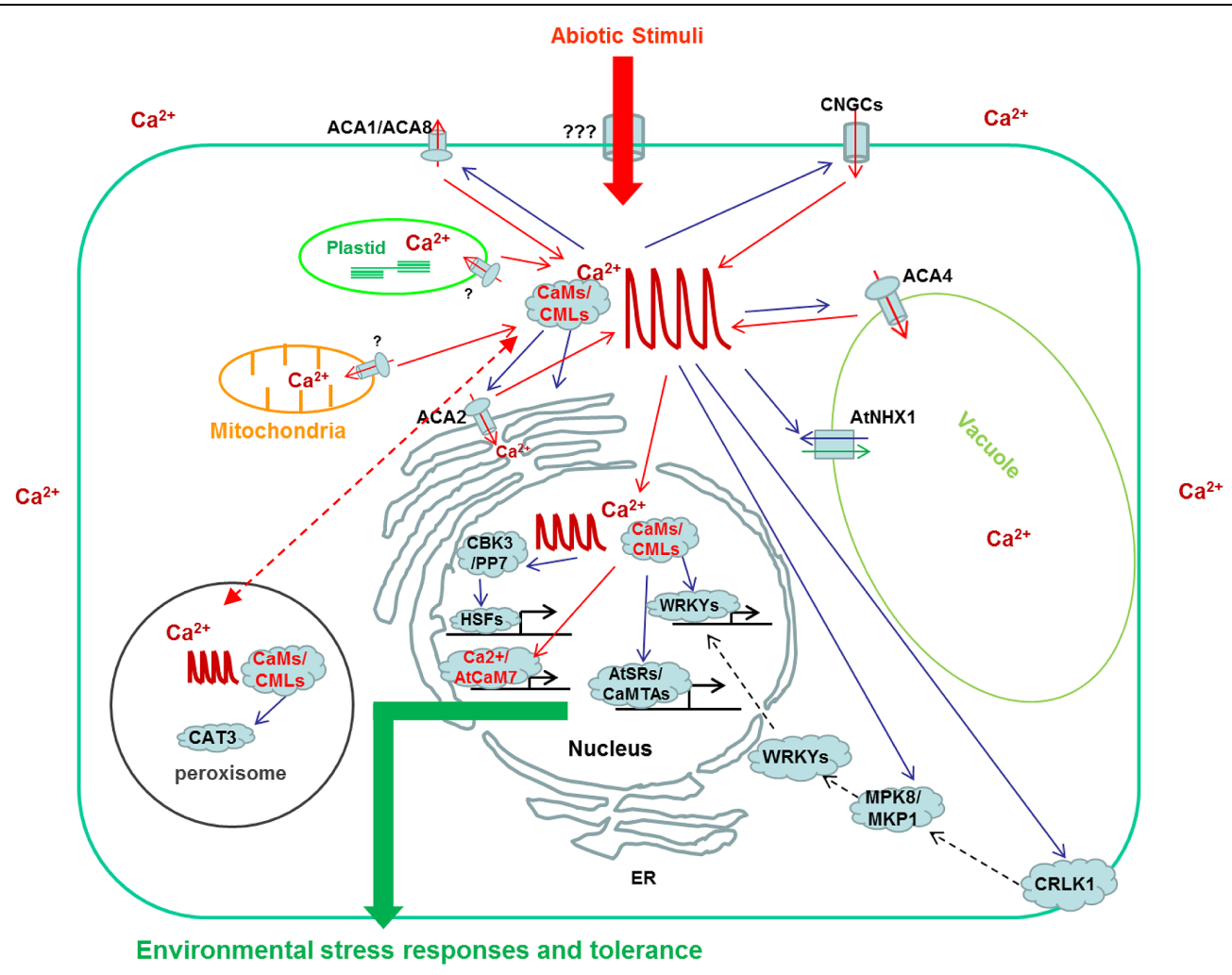

FIGURE 1|Schematic representation of $\mathrm{Ca}^{2+}$ transients and their modification and interpretation by CaM/CMLs as well as their target proteins in plant cells under abiotic stresses. This model is not exhaustive and only includes the actions of a limited number of CaM/CMLs and target proteins; CaMs/CMLs/CBPs involved in biotic stresses and $\mathrm{Ca}^{2+}$ signal interpretation by other sensors such as CBLs and CDPKs are not included. Actions modifing $\mathrm{Ca}^{2+}$ transients or $\mathrm{CaM} / \mathrm{CMLs}$ are presented by red arrows and actions regulated by $\mathrm{Ca}^{2+} / \mathrm{CaMs}$ or $\mathrm{Ca}^{2+} / \mathrm{CMLs}$ are presented by blue arrows. The dashed arrows imply multiple regulations extended to nucleus. 
CaMs and CMLs especially those interact with CMLs deserve special attentions. Environmental cues are known to trigger stimulus specific $\mathrm{Ca}^{2+}$ transients. In an effort to explain how the simple $\mathrm{Ca}^{2+}$ ion could act as a messenger to couple various environmental stimuli to appropriate physiological responses with astonishing accuracy, Webb et al. (1996) proposed the theory of " $\mathrm{Ca}^{2+}$ signature" which hypothesized that stimulustriggered increases in intracellular $\mathrm{Ca}^{2+}$ concentration vary in terms of duration, frequency, amplitude, and spatial distribution, and these carry specific information when they are interpreted into different physiological responses. An obvious support for this hypothesis is that the different $\mathrm{Ca}^{2+}$ spikes triggered by Nod factor from rhizobia and Myc factor from arbuscular mycorrhizal fungi could be interpreted through the action of the same $\mathrm{Ca}^{2+}, \mathrm{Ca}^{2+} / \mathrm{CaM}$ dependent protein kinase, $\mathrm{CCaMK}$, into different physiological responses to support the establishment of root nodulation symbiosis or arbuscular mycorrhization (Kosuta et al., 2008). Although exciting progress on how $\mathrm{Ca}^{2+}$ signals are interpreted into various physiological responses has been made in the last decade, what we know so far may be very

\section{References}

Abe, H., Urao, T., Ito, T., Seki, M., Shinozaki, K., and Yamaguchi-Shinozaki, K. (2003). Arabidopsis AtMYC2 (bHLH) and AtMYB2 (MYB) function as transcriptional activators in abscisic acid signaling. Plant Cell 15, 63-78. doi: 10.1105/tpc.006130

Apel, K., and Hirt, H. (2004). Reactive oxygen species: metabolism, oxidative stress, and signal transduction. Annu. Rev. Plant Biol. 55, 373-399. doi: 10.1146/annurev.arplant.55.031903.141701

Apse, M. P., Aharon, G. S., Snedden, W. A., and Blumwald, E. (1999). Salt tolerance conferred by overexpression of a vacuolar $\mathrm{Na}+/ \mathrm{H}+$ antiport in Arabidopsis. Science 285, 1256-1258. doi: 10.1126/science.285.5431.1256

Arazi, T., Sunkar, R., Kaplan, B., and Fromm, H. (1999). A tobacco plasma membrane calmodulin-binding transporter confers $\mathrm{Ni} 2+$ tolerance and $\mathrm{Pb} 2+$ hypersensitivity in transgenic plants. Plant J. 20, 171-182. doi: 10.1046/j.1365313x.1999.00588.x

Aurisano, N., Bertani, A., and Reggiani, R. (1995). Involvement of calcium and calmodulin in protein and amino acid metabolism in rice roots under anoxia. Plant Cell Physiol. 36, 1525-1529. doi: 10.1080/112635095094 40949

Boonburapong, B., and Buaboocha, T. (2007). Genome-wide identification and analyses of the rice calmodulin and related potential calcium sensor proteins. BMC Plant Biology 7:4. doi: 10.1186/1471-2229-7-4

Botella, J. R., and Arteca, R. N. (1994). Differential expression of two calmodulin genes in response to physical and chemical stimuli. Plant Mol. Biol. 24, 757-766. doi: 10.1007/BF00029857

Bouche, N., Fait, A., Bouchez, D., Moller, S. G., and Fromm, H. (2003). Mitochondrial succinic-semialdehyde dehydrogenase of the gammaaminobutyrate shunt is required to restrict levels of reactive oxygen intermediates in plants. Proc. Natl. Acad. Sci. U.S.A. 100, 6843-6848. doi: 10.1073/pnas.1037532100

Bouche, N., Scharlat, A., Snedden, W., Bouchez, D., and Fromm, H. (2002). A novel family of calmodulin-binding transcription activators in multicellular organisms. J. Biol. Chem. 277, 21851-21861. doi: 10.1074/jbc.M2002 68200

Bouche, N., Yellin, A., Snedden, W. A., and Fromm, H. (2005). Plant-specific calmodulin-binding proteins. Annu. Rev. Plant Biol. 56, 435-466. doi: 10.1146/annurev.arplant.56.032604.144224

Boursiac, Y., Lee, S. M., Romanowsky, S., Blank, R., Sladek, C., Chung, W. S., et al. (2010). Disruption of the vacuolar calcium-ATPases in Arabidopsis results in the activation of a salicylic acid-dependent programmed cell death pathway. Plant Physiol. 154, 1158-1171. doi: 10.1104/pp.110.159038 limited in scope when one considers the complicated $\mathrm{Ca}^{2+}$ signaling network. Many issues such as specificity, preference and flexibility of interaction between various CaM/CMLs and target proteins in planta are barely understood. The dynamics of $\mathrm{Ca}^{2+} / \mathrm{CaM}$ mediated regulation, the mechanistic details by which a particular effector detects a difference in $\mathrm{Ca}^{2+}$ signature and initiates distinct signaling pathways, are basically unknown. Progress in addressing these issues will help in understanding the most amazing properties, the versatility, efficiency and accuracy of $\mathrm{Ca}^{2+}$-mediated signaling in plant responses to environmental stresses.

\section{Acknowledgments}

Research of the authors is supported by the National Natural Science Foundation of China grants (U1130304 and 31201679), Zhejiang Provincial Natural Science Foundation of China grant (LY15C020006) and US National Science Foundation grant (1021344).

Braam, J. (1992). Regulated expression of the calmodulin-related TCH genes in cultured Arabidopsis cells: induction by calcium and heat shock. Proc. Natl. Acad. Sci. U.S.A. 89, 3213-3216. doi: 10.1073/pnas.89.8.3213

Cha, J.-Y., Su'udi, M., Kim, W.-Y., Kim, D. R., Kwak, Y.-S., and Son, D. (2012). Functional characterization of orchardgrass cytosolic Hsp70 (DgHsp70) and the negative regulation by Ca2+/AtCaM2 binding. Plant Physiol. Biochem. 58, 29-36. doi: 10.1016/j.plaphy.2012.06.006

Chinnusamy, V., Schumaker, K., and Zhu, J.-K. (2004). Molecular genetic perspectives on cross-talk and specificity in abiotic stress signalling in plants. J. Exp. Bot. 55, 225-236. doi: 10.1093/jxb/erh005

Choi, M. S., Kim, M. C., Yoo, J. H., Moon, B. C., Koo, S. C., Park, B. O., et al. (2005). Isolation of a calmodulin-binding transcription factor from rice (Oryza sativa L.). J. Biol. Chem. 280, 40820-40831. doi: 10.1074/jbc.M504616200

Chung, W. S., Lee, S. H., Kim, J. C., Heo, W. D., Kim, M. C., Park, C. Y., et al. (2000). Identification of a calmodulin-regulated soybean $\mathrm{Ca}(2+)$-ATPase (SCA1) that is located in the plasma membrane. Plant Cell 12, 1393-1407. doi: $10.2307 / 3871138$

Delk, N. A., Johnson, K. A., Chowdhury, N. I., and Braam, J. (2005). CML24, regulated in expression by diverse stimuli, encodes a potential Ca2+ sensor that functions in responses to abscisic acid, daylength, and ion stress. Plant Physiol. 139, 240-253. doi: 10.1104/pp.105.062612

Deswal, R., and Sopory, S. K. (1999). Glyoxalase I from Brassica juncea is a calmodulin stimulated protein. Biochim. Biophys. Acta 1450, 460-467. doi: 10.1016/S0167-4889(99)00047-6

Dobney, S., Chiasson, D., Lam, P., Smith, S. P., and Snedden, W. A. (2009). The calmodulin-related calcium sensor CML42 plays a role in trichome branching. J. Biol. Chem. 284, 31647-31657. doi: 10.1074/jbc.M109.056770

Dodd, A. N., Kudla, J., and Sanders, D. (2010). The language of calcium signaling. Annu. Rev. Plant Biol. 61, 593-620. doi: 10.1146/annurev-arplant-070109104628

Doherty, C. J., Van Buskirk, H. A., Myers, S. J., and Thomashow, M. F. (2009). Roles for Arabidopsis CAMTA transcription factors in cold-regulated gene expression and freezing tolerance. Plant Cell 21, 972-984. doi: 10.1105/tpc.108.063958

Du, L., Ali, G. S., Simons, K. A., Hou, J., Yang, T., Reddy, A. S. N., et al. (2009). $\mathrm{Ca}+/$ calmodulin regulates salicylic-acid-mediated plant immunity. Nature 457, 1154-1158. doi: 10.1038/nature07612

Du, L., and Poovaiah, B. W. (2004). A novel family of Ca2+/calmodulinbinding proteins involved in transcriptional regulation: interaction with fsh/Ring3 class transcription activators. Plant Mol. Biol. 54, 549-569. doi: 10.1023/B:PLAN.0000038269.98972.bb

Du, L., and Poovaiah, B. W. (2005). Ca2+/calmodulin is critical for brassinosteroid biosynthesis and plant growth. Nature 437, 741-745. doi: 10.1038/nature03973 
Du, L., Yang, T., Puthanveettil, S. V., Poovaiah, B. W., and Luan, S. (2011). "Decoding of calcium signal through calmodulin: calmodulin-binding proteins in plants coding and decoding of calcium signals in plants," in Coding and Decoding of Calcium Signals in Plants, ed. S. Luan (Berlin: Springer), 177-233.

Evans, N. H., Mcainsh, M. R., and Hetherington, A. M. (2001). Calcium oscillations in higher plants. Curr. Opin. Plant Biol. 4, 415-420. doi: 10.1016/S13695266(00)00194-1

Fromm, H., and Chua, N.-H. (1992). Cloning of plant cDNAs encoding calmodulin-binding proteins using 35S-labeled recombinant calmodulin as a probe. Plant Mol. Biol. Rep. 10, 199-206. doi: 10.1007/BF02668347

Galon, Y., Aloni, R., Nachmias, D., Snir, O., Feldmesser, E., Scrase-Field, S., et al. (2010). Calmodulin-binding transcription activator 1 mediates auxin signaling and responds to stresses in Arabidopsis. Planta 232, 165-178. doi: 10.1007/s00425-010-1153-6

Geisler, M., Frangne, N., Gomes, E., Martinoia, E., and Palmgren, M. G. (2000). The ACA4 gene of Arabidopsis encodes a vacuolar membrane calcium pump that improves salt tolerance in yeast. Plant Physiol. 124, 1814-1827. doi: 10.1104/pp.124.4.1814

Gleason, C., Chaudhuri, S., Yang, T., Munoz, A., Poovaiah, B. W., and Oldroyd, G. E. (2006). Nodulation independent of rhizobia induced by a calcium-activated kinase lacking autoinhibition. Nature 441, 1149-1152. doi: 10.1038 /nature04812

Gong, M., Chen, S.-N., Song, Y.-Q., and Li, Z.-G. (1997a). Effect of calcium and calmodulin on intrinsic heat tolerance in relation to antioxidant systems in maize seedlings. Funct. Plant Biol. 24, 371-379. doi: 10.1071/pp96118

Gong, M., Li, Y.-J., Dai, X., Tian, M., and Li, Z.-G. (1997b). Involvement of calcium and calmodulin in the acquisition of heat-shock induced thermotolerance in maize seedlings. J. Plant Physiol. 150, 615-621. doi: 10.1016/S01761617(97)80328-8

Gong, M., and Li, Z.-G. (1995). Calmodulin-binding proteins from Zea mays germs. Phytochemistry 40, 1335-1339. doi: 10.1016/0031-9422(95)00381-G

Gong, M., Van Der Luit, A. H., Knight, M. R., and Trewavas, A. J. (1998). Heat-shock-induced changes in intracellular Ca2+ level in tobacco seedlings in relation to thermotolerance. Plant Physiol. 116, 429-437. doi: 10.1104/pp.116.1.429

Gould, K. S., Lamotte, O., Klinguer, A., Pugin, A., and Wendehenne, D. (2003). Nitric oxide production in tobacco leaf cells: a generalized stress response? Plant Cell Environ. 26, 1851-1862. doi: 10.1046/j.1365-3040.2003.01101.x

Hannah, M. A., Heyer, A. G., and Hincha, D. K. (2005). A global survey of gene regulation during cold acclimation in Arabidopsis thaliana. PLoS Genet 1:e26. doi: 10.1371 /journal.pgen.0010026

Harding, S. A., Oh, S. H., and Roberts, D. M. (1997). Transgenic tobacco expressing a foreign calmodulin gene shows an enhanced production of active oxygen species. EMBO J. 16, 1137-1144. doi: 10.1093/emboj/16.6.1137

Hill, K., Wang, H., and Perry, S. E. (2008). A transcriptional repression motif in the MADS factor AGL15 is involved in recruitment of histone deacetylase complex components. Plant J. 53, 172-185. doi: 10.1111/j.1365-313X.2007. 03336.x

Hoeflich, K. P., and Ikura, M. (2002). Calmodulin in action: diversity in target recognition and activation mechanisms. Cell 108, 739-742. doi: 10.1016/S00928674(02)00682-7

Karita, E., Yamakawa, H., Mitsuhara, I., Kuchitsu, K., and Ohashi, Y. (2004). Three types of tobacco calmodulins characteristically activate plant NAD kinase at different Ca2 + concentrations and pHs. Plant Cell Physiol. 45, 1371-1379. doi: $10.1093 / \mathrm{pcp} / \mathrm{pch} 158$

Kim, M. C., Chung, W. S., Yun, D. J., and Cho, M. J. (2009). Calcium and calmodulin-mediated regulation of gene expression in plants. Mol. Plant 2, 13-21. doi: 10.1093/mp/ssn091

Kim, M. C., Panstruga, R., Elliott, C., Muller, J., Devoto, A., Yoon, H. W., et al. (2002). Calmodulin interacts with MLO protein to regulate defence against mildew in barley. Nature 416, 447-451. doi: 10.1038/416447a

Kim, Y., Park, S., Gilmour, S. J., and Thomashow, M. F. (2013). Roles of CAMTA transcription factors and salicylic acid in configuring the low-temperature transcriptome and freezing tolerance of Arabidopsis. Plant J. 75, 364-376. doi: 10.1111/tpj.12205

Knight, M. R., Campbell, A. K., Smith, S. M., and Trewavas, A. J. (1991). Transgenic plant aequorin reports the effects of touch and cold-shock and elicitors on cytoplasmic calcium. Nature 352, 524-526. doi: 10.1038/352524a0
Kosuta, S., Hazledine, S., Sun, J., Miwa, H., Morris, R. J., Downie, J. A., et al. (2008). Differential and chaotic calcium signatures in the symbiosis signaling pathway of legumes. Proc. Natl. Acad. Sci. U.S.A. 105, 9823-9828. doi: 10.1073/pnas.0803499105

Kudla, J., Batistic, O., and Hashimoto, K. (2010). Calcium signals: the lead currency of plant information processing. Plant Cell 22, 541-563. doi: 10.1105/tpc.109.072686

Kushwaha, R., Singh, A., and Chattopadhyay, S. (2008). Calmodulin7 plays an important role as transcriptional regulator in Arabidopsis seedling development. Plant Cell 20, 1747-1759. doi: 10.1105/tpc.107.057612

Kutuzov, M. A., Bennett, N., and Andreeva, A. V. (2001). Interaction of plant protein Ser/Thr phosphatase PP7 with calmodulin. Biochem. Biophys. Res. Commun. 289, 634-640. doi: 10.1006/bbrc.2001.6020

Larkindale, J., and Knight, M. R. (2002). Protection against heat stress-induced oxidative damage in Arabidopsis involves calcium, abscisic acid, ethylene, and salicylic acid. Plant Physiol. 128, 682-695. doi: 10.1104/pp.010320

Lee, S. H., Johnson, J. D., Walsh, M. P., Van Lierop, J. E., Sutherland, C., Xu, A. D., et al. (2000). Differential regulation of $\mathrm{Ca} 2+/$ calmodulin-dependent enzymes by plant calmodulin isoforms and free $\mathrm{Ca} 2+$ concentration. Biochem. J. 350, 299-306. doi: 10.1042/0264-6021:3500299

Li, X., Huang, L., Zhang, Y., Ouyang, Z., Hong, Y., Zhang, H., et al. (2014). Tomato SR/CAMTA transcription factors SISR1 and SISR3L negatively regulate disease resistance response and SISR1L positively modulates drought stress tolerance. BMC Plant Biol. 14:286. doi: 10.1186/s12870-014-0286-3

Liu, H. T., Gao, F., Li, G. L., Han, J. L., Liu, D. L., Sun, D. Y., et al. (2008). The calmodulin-binding protein kinase 3 is part of heat-shock signal transduction in Arabidopsis thaliana. Plant J. 55, 760-773. doi: 10.1111/j.1365313X.2008.03544.x

Liu, H. T., Li, B., Shang, Z. L., Li, X. Z., Mu, R. L., Sun, D. Y., et al. (2003). Calmodulin is involved in heat shock signal transduction in wheat. Plant Physiol. 132, 1186-1195. doi: 10.1104/pp.102.018564

Liu, H. T., Li, G. L., Chang, H., Sun, D. Y., Zhou, R. G., and Li, B. (2007). Calmodulin-binding protein phosphatase PP7 is involved in thermotolerance in Arabidopsis. Plant Cell Environ. 30, 156-164. doi: 10.1111/j.13653040.2006.01613.x

Liu, H.-T., Sun, D.-Y., and Zhou, R.-G. (2005). Ca2+ and AtCaM3 are involved in the expression of heat shock protein gene in Arabidopsis. Plant Cell Environ. 28, 1276-1284. doi: 10.1111/j.1365-3040.2005.01365.x

Lu, Y. T., Dharmasiri, M. A., and Harrington, H. M. (1995). Characterization of a cDNA encoding a novel heat-shock protein that binds to calmodulin. Plant Physiol. 108, 1197-1202. doi: 10.1104/pp.108.3.1197

Luan, S. (2009). The CBL-CIPK network in plant calcium signaling. Trends Plant Sci. 14, 37-42. doi: 10.1016/j.tplants.2008.10.005

Ma, F. F., Lu, R., Liu, H. Y., Shi, B., Zhang, J. H., Tan, M. P., et al. (2012). Nitric oxide-activated calcium/calmodulin-dependent protein kinase regulates the abscisic acid-induced antioxidant defence in maize. J. Exp. Bot. 63, 4835-4847. doi: 10.1093/jxb/ers161

Magnan, F., Ranty, B., Charpenteau, M., Sotta, B., Galaud, J. P., and Aldon, D. (2008). Mutations in AtCML9, a calmodulin-like protein from Arabidopsis thaliana, alter plant responses to abiotic stress and abscisic acid. Plant J. 56, 575-589. doi: 10.1111/j.1365-313X.2008.03622.x

Mahajan, S., Pandey, G. K., and Tuteja, N. (2008). Calcium- and salt-stress signaling in plants: shedding light on SOS pathway. Arch. Biochem. Biophys. 471, 146-158. doi: 10.1016/j.abb.2008.01.010

Mandadi, K. K., Misra, A., Ren, S., and Mcknight, T. D. (2009). BT2, a BTB protein, mediates multiple responses to nutrients, stresses, and hormones in Arabidopsis. Plant Physiol. 150, 1930-1939. doi: 10.1104/pp.109.139220

McCormack, E., and Braam, J. (2003). Calmodulins and related potential calcium sensors of Arabidopsis. New Phytol. 159, 585-598. doi: 10.1046/j.14698137.2003.00845.x

McCormack, E., Tsai, Y.-C., and Braam, J. (2005). Handling calcium signaling: Arabidopsis CaMs and CMLs. Trends Plant Sci. 10, 383-389. doi: 10.1016/j.tplants.2005.07.001

Medda, R., Padiglia, A., Longu, S., Bellelli, A., Arcovito, A., Cavallo, S., et al. (2003). Critical role of $\mathrm{Ca} 2+$ ions in the reaction mechanism of Euphorbia characias peroxidase. Biochemistry 42, 8909-8918. doi: 10.1021/bi034609z

Mura, A., Medda, R., Longu, S., Floris, G., Rinaldi, A. C., and Padiglia, A. (2005). A Ca2+/calmodulin-binding peroxidase from Euphorbia latex: novel aspects 
of calcium-hydrogen peroxide cross-talk in the regulation of plant defenses. Biochemistry 44, 14120-14130. doi: 10.1021/bi0513251

Pandey, N., Ranjan, A., Pant, P., Tripathi, R. K., Ateek, F., Pandey, H. P., et al. (2013). CAMTA 1 regulates drought responses in Arabidopsis thaliana. BMC Genomics 14:216. doi: 10.1186/1471-2164-14-216

Pandey, S., Tiwari, S. B., Tyagi, W., Reddy, M. K., Upadhyaya, K. C., and Sopory, S. K. (2002). A Ca2+/CaM-dependent kinase from pea is stress regulated and in vitro phosphorylates a protein that binds to AtCaM5 promoter. Eur. J. Biochem. 269, 3193-3204. doi: 10.1046/j.1432-1033.2002.02994.x

Park, C. Y., Lee, J. H., Yoo, J. H., Moon, B. C., Choi, M. S., Kang, Y. H., et al. (2005). WRKY group IId transcription factors interact with calmodulin. FEBS Lett. 579, 1545-1550. doi: 10.1016/j.febslet.2005.01.057

Park, H. C., Kim, M. L., Kang, Y. H., Jeon, J. M., Yoo, J. H., Kim, M. C., et al. (2004). Pathogen- and $\mathrm{NaCl}$-induced expression of the SCaM-4 promoter is mediated in part by a GT-1 box that interacts with a GT-1-like transcription factor. Plant Physiol. 135, 2150-2161. doi: 10.1104/pp.104.041442

Park, H. C., Park, C. Y., Koo, S. C., Cheong, M. S., Kim, K. E., Kim, M. C., et al. (2010). AtCML8, a calmodulin-like protein, differentially activating CaMdependent enzymes in Arabidopsis thaliana. Plant Cell Rep. 29, 1297-1304. doi: 10.1007/s00299-010-0916-7

Pauly, N., Knight, M. R., Thuleau, P., Van Der Luit, A. H., Moreau, M., Trewavas, A. J., et al. (2000). Control of free calcium in plant cell nuclei. Nature 405, 754-755. doi: $10.1038 / 35015671$

Perochon, A., Aldon, D., Galaud, J.-P., and Ranty, B. (2011). Calmodulin and calmodulin-like proteins in plant calcium signaling. Biochimie 93, 2048-2053. doi: 10.1016/j.biochi.2011.07.012

Perruc, E., Charpenteau, M., Ramirez, B. C., Jauneau, A., Galaud, J. P., Ranjeva, R., et al. (2004). A novel calmodulin-binding protein functions as a negative regulator of osmotic stress tolerance in Arabidopsis thaliana seedlings. Plant $\mathrm{J}$. 38, 410-420. doi: 10.1111/j.1365-313X.2004.02062.x

Polisensky, D. H., and Braam, J. (1996). Cold-shock regulation of the Arabidopsis TCH genes and the effects of modulating intracellular calcium levels. Plant Physiol. 111, 1271-1279. doi: 10.1104/pp.111.4.1271

Poovaiah, B. W., Du, L., Wang, H., and Yang, T. (2013). Recent advances in calcium/calmodulin-mediated signaling with an emphasis on plant-microbe interactions. Plant Physiol. 163, 531-542. doi: 10.1104/pp.113.220780

Poovaiah, B. W., and Reddy, A. S. (1993). Calcium and signal transduction in plants. CRC Crit. Rev. Plant Sci. 12, 185-211. doi: 10.1080/713608046

Popescu, S. C., Popescu, G. V., Bachan, S., Zhang, Z., Seay, M., Gerstein, M., et al. (2007). Differential binding of calmodulin-related proteins to their targets revealed through high-density Arabidopsis protein microarrays. Proc. Natl. Acad. Sci. U.S.A. 104, 4730-4735. doi: 10.1073/pnas.0611615104

Price, A. H., Taylor, A., Ripley, S. J., Griffiths, A., Trewavas, A. J., and Knight, M. R. (1994). Oxidative signals in tobacco increase cytosolic calcium. Plant Cell 6, 1301-1310. doi: 10.1105/tpc.6.9.1301

Reddy, A. S. N. (2001). Calcium: silver bullet in signaling. Plant Sci. 160, 381-404. doi: 10.1016/S0168-9452(00)00386-1

Reddy, A. S., Ali, G. S., Celesnik, H., and Day, I. S. (2011). Coping with stresses: roles of calcium- and calcium/calmodulin-regulated gene expression. Plant Cell 23, 2010-2032. doi: 10.1105/tpc.111.084988

Reddy, A. S. N., Reddy, V. S., and Golovkin, M. (2000). A calmodulin binding protein from Arabidopsis is induced by ethylene and contains a DNA-binding motif. Biochem. Biophys. Res. Commun. 279, 762-769. doi: 10.1006/bbrc. 2000.4032

Reddy, A. S. N., Takezawa, D., Fromm, H., and Poovaiah, B. W. (1993). Isolation and characterization of 2 cdnas that encode for calmodulin-binding proteins from corn root-tips. Plant Sci. 94, 109-117. doi: 10.1016/0168-9452(93)90012-O

Reddy, V. S., Ali, G. S., and Reddy, A. S. (2002). Genes encoding calmodulinbinding proteins in the Arabidopsis genome. J. Biol. Chem. 277, 9840-9852. doi: 10.1074/jbc.M111626200

Rentel, M. C., and Knight, M. R. (2004). Oxidative stress-induced calcium signaling in Arabidopsis. Plant Physiol. 135, 1471-1479. doi: 10.1104/pp.104.042663

Rhoads, A. R., and Friedberg, F. (1997). Sequence motifs for calmodulin recognition. FASEB J. 11, 331-340.

Rivetta, A., Negrini, N., and Cocucci, M. (1997). Involvement of Ca2+-calmodulin in $\mathrm{Cd} 2+$ toxicity during the early phases of radish (Raphanus sativus L.) seed germination. Plant Cell Environ. 20, 600-608. doi: 10.1111/j.13653040.1997.00072.x
Ruiz, J. M., Sanchez, E., Garcia, P. C., Lopez-Lefebre, L. R., Rivero, R. M., and Romero, L. (2002). Proline metabolism and NAD kinase activity in greenbean plants subjected to cold-shock. Phytochemistry 59, 473-478. doi: 10.1016/S0031-9422(01)00481-2

Shi, B., Ni, L., Zhang, A., Cao, J., Zhang, H., Qin, T., et al. (2012). OsDMI3 is a novel component of abscisic acid signaling in the induction of antioxidant defense in leaves of rice. Mol. Plant 5, 1359-1374. doi: 10.1093/mp/sss068

Singla-Pareek, S. L., Reddy, M. K., and Sopory, S. K. (2003). Genetic engineering of the glyoxalase pathway in tobacco leads to enhanced salinity tolerance. Proc. Natl. Acad. Sci. U.S.A. 100, 14672-14677. doi: 10.1073/pnas.2034667100

Snedden, W. A., and Fromm, H. (1998). Calmodulin, calmodulin-related proteins and plant responses to the environment. Trends Plant Sci. 3, 299-304. doi: 10.1016/S1360-1385(98)01284-9

Snedden, W. A., and Fromm, H. (2001). Calmodulin as a versatile calcium signal transducer in plants. New Phytol. 151, 35-66. doi: 10.1046/j.14698137.2001.00154.x

Snedden, W. A., Koutsia, N., Baum, G., and Fromm, H. (1996). Activation of a recombinant Petunia glutamate decarboxylase by calcium/calmodulin or by a monoclonal antibody which recognizes the calmodulin binding domain. J. Biol. Chem. 271, 4148-4153. doi: 10.1074/jbc.271.8.4148

Song, L. L., Ding, W., Zhao, M. G., Sun, B. T., and Zhang, L. X. (2006). Nitric oxide protects against oxidative stress under heat stress in the calluses from two ecotypes of reed. Plant Sci. 171, 449-458. doi: 10.1016/j.plantsci.2006.05.002

Subbaiah, C. C., and Sachs, M. M. (2000). Maize cap1 encodes a novel SERCAtype calcium-ATPase with a calmodulin-binding domain. J. Biol. Chem. 275, 21678-21687. doi: 10.1074/jbc.M001484200

Sun, X. T., Li, B., Zhou, G. M., Tang, W. Q., Bai, J., Sun, D. Y., et al. (2000). Binding of the maize cytosolic Hsp70 to calmodulin, and identification of calmodulinbinding site in Hsp70. Plant Cell Physiol. 41, 804-810. doi: 10.1093/pcp/41. 6.804

Sunkar, R., Kaplan, B., Bouche, N., Arazi, T., Dolev, D., Talke, I. N., et al. (2000). Expression of a truncated tobacco NtCBP4 channel in transgenic plants and disruption of the homologous Arabidopsis $\mathrm{CNGC1}$ gene confer $\mathrm{Pb} 2+$ tolerance. Plant J. 24, 533-542. doi: 10.1046/j.1365-313x.2000.00901.x

Takahashi, F., Mizoguchi, T., Yoshida, R., Ichimura, K., and Shinozaki, K. (2011). Calmodulin-dependent activation of MAP kinase for ROS homeostasis in Arabidopsis. Mol. Cell. 41, 649-660. doi: 10.1016/j.molcel.2011.02.029

Takezawa, D., and Minami, A. (2004). Calmodulin-binding proteins in bryophytes: identification of abscisic acid-, cold-, and osmotic stress-induced genes encoding novel membrane-bound transporter-like proteins. Biochem. Biophys. Res. Commun. 317, 428-436. doi: 10.1016/j.bbrc.2004.03.052

Thornalley, P. J. (1990). The glyoxalase system: new developments towards functional characterization of a metabolic pathway fundamental to biological life. Biochem. J. 269, 1-11.

Tirichine, L., Imaizumi-Anraku, H., Yoshida, S., Murakami, Y., Madsen, L. H., Miwa, H., et al. (2006). Deregulation of a Ca2+/calmodulin-dependent kinase leads to spontaneous nodule development. Nature 441, 1153-1156. doi: 10.1038/nature04862

Townley, H. E., and Knight, M. R. (2002). Calmodulin as a potential negative regulator of Arabidopsis COR gene expression. Plant Physiol. 128, 1169-1172. doi: $10.1104 /$ pp.010814

Turner, W. L., Waller, J. C., Vanderbeld, B., and Snedden, W. A. (2004). Cloning and characterization of two NAD kinases from Arabidopsis. identification of a calmodulin binding isoform. Plant Physiol. 135, 1243-1255. doi: 10.1104/pp.104.040428

Uchida, A., Jagendorf, A. T., Hibino, T., Takabe, T., and Takabe, T. (2002). Effects of hydrogen peroxide and nitric oxide on both salt and heat stress tolerance in rice. Plant Sci. 163, 515-523. doi: 10.1016/S0168-9452(02)00159-0

Vadassery, J., Reichelt, M., Hause, B., Gershenzon, J., Boland, W., and Mithofer, A. (2012). CML42-mediated calcium signaling coordinates responses to Spodoptera herbivory and abiotic stresses in Arabidopsis. Plant Physiol. 159, 1159-1175. doi: 10.1104/pp.112.198150

Van Breusegem, F., Vranov, E., Dat, J. F., and Inz, D. (2001). The role of active oxygen species in plant signal transduction. Plant Sci. 161, 405-414. doi: 10.1016/S0168-9452(01)00452-6

Vanderbeld, B., and Snedden, W. A. (2007). Developmental and stimulus-induced expression patterns of Arabidopsis calmodulin-like genes CML37, CML38 and CML39. Plant Mol. Biol. 64, 683-697. doi: 10.1007/s11103-007-9189-0 
Van Der Luit, A. H., Olivari, C., Haley, A., Knight, M. R., and Trewavas, A. J. (1999). Distinct calcium signaling pathways regulate calmodulin gene expression in tobacco. Plant Physiol. 121, 705-714. doi: 10.1104/pp.121.3.705

Veena, A., Reddy, V. S., and Sopory, S. K. (1999). Glyoxalase I from Brassica juncea: molecular cloning, regulation and its over-expression confer tolerance in transgenic tobacco under stress. Plant J. 17, 385-395. doi: 10.1046/j.1365313X.1999.00390.x

Wan, D. L., Li, R. L., Zou, B., Zhang, X., Cong, J. Y., Wang, R. G., et al. (2012). Calmodulin-binding protein CBP60g is a positive regulator of both disease resistance and drought tolerance in Arabidopsis. Plant Cell Rep. 31, 1269-1281. doi: 10.1007/s00299-012-1247-7

Wang, G., Zeng, H., Hu, X., Zhu, Y., Chen, Y., Shen, C., et al. (2015). Identification and expression analyses of calmodulin-binding transcription activator genes in soybean. Plant Soil 386, 205-221. doi: 10.1007/s11104-014-2267-6

Wang, L., Tsuda, K., Sato, M., Cohen, J. D., Katagiri, F., and Glazebrook, J. (2009). Arabidopsis CaM binding protein CBP60g contributes to MAMP-induced SA accumulation and is involved in disease resistance against Pseudomonas syringae. PLoS Pathog 5:e1000301. doi: 10.1371/journal.ppat.1000301

Wang, X.-H., Li, Q.-T., Chen, H.-W., Zhang, W.-K., Ma, B., Chen, S.-Y., et al. (2014). Trihelix transcription factor GT-4 mediates salt tolerance via interaction with TEM2 in Arabidopsis. BMC Plant Biol. 14:339. doi: 10.1186/s12870-0140339-7

Wang, Y., Liang, S., Xie, Q. G., and Lu, Y. T. (2004). Characterization of a calmodulin-regulated $\mathrm{Ca} 2+$-dependent-protein-kinase-related protein kinase, AtCRK1, from Arabidopsis. Biochem. J. 383, 73-81. doi: 10.1042/BJ20031907

Webb, A. A. R., Mcainsh, M. R., Taylor, J. E., and Hetherington, A. M. (1996). "Calcium ions as intracellular second messengers in higher plants," in Advances in Botanical Research, ed. J. A. Callow (Waltham, MA: Academic Press), 45-96.

Weng, H., Yoo, C. Y., Gosney, M. J., Hasegawa, P. M., and Mickelbart, M. V. (2012). Poplar GTL1 is a Ca2+/calmodulin-binding transcription factor that functions in plant water use efficiency and drought tolerance. PLoS ONE 7:e32925. doi: 10.1371/journal.pone.0032925

$\mathrm{Wu}, \mathrm{H}$. C., and Jinn, T. L. (2012). Oscillation regulation of $\mathrm{Ca}(2+) /$ calmodulin and heat-stress related genes in response to heat stress in rice (Oryza sativa L.). Plant Signal Behav. 7, 1056-1057. doi: 10.4161/psb.21124

Wu, H. C., Luo, D. L., Vignols, F., and Jinn, T. L. (2012). Heat shockinduced biphasic $\mathrm{Ca} 2+$ signature and OsCaM1-1 nuclear localization mediate downstream signalling in acquisition of thermotolerance in rice (Oryza sativa L.). Plant Cell Environ. 35, 1543-1557. doi: 10.1111/j.1365-3040.2012.02508.x

Xi, J., Qiu, Y., Du, L., and Poovaiah, B. W. (2012). Plant-specific trihelix transcription factor AtGT2L interacts with calcium/calmodulin and responds to cold and salt stresses. Plant Sci. 185-186, 274-280. doi: 10.1016/j.plantsci.2011.11.013

Xing, T., Higgins, V. J., and Blumwald, E. (1997). Race-specific elicitors of Cladosporium fulvum promote translocation of cytosolic components of NADPH oxidase to the plasma membrane of tomato cells. Plant Cell 9, 249-259. doi: 10.1105/tpc.9.2.249

Xiong, L., and Zhu, J. K. (2002). Molecular and genetic aspects of plant responses to osmotic stress. Plant Cell Environ. 25, 131-139. doi: 10.1046/j.13653040.2002.00782.x

Xu, G. Y., Rocha, P. S., Wang, M. L., Xu, M. L., Cui, Y. C., Li, L. Y., et al. (2011). A novel rice calmodulin-like gene, OsMSR2, enhances drought and salt tolerance and increases ABA sensitivity in Arabidopsis. Planta 234, 47-59. doi: $10.1007 / \mathrm{s} 00425-011-1386-\mathrm{Z}$

Xuan, Y., Zhou, S., Wang, L., Cheng, Y. D., and Zhao, L. Q. (2010). Nitric oxide functions as a signal and acts upstream of AtCaM3 in thermotolerance in Arabidopsis seedlings. Plant Physiol. 153, 1895-1906. doi: 10.1104/pp.110.160424

Yamaguchi, T., Aharon, G. S., Sottosanto, J. B., and Blumwald, E. (2005). Vacuolar $\mathrm{Na} / / \mathrm{H}+$ antiporter cation selectivity is regulated by calmodulin from within the vacuole in a Ca2+- and $\mathrm{pH}$-dependent manner. Proc. Natl. Acad. Sci. U.S.A. 102, 16107-16112. doi: 10.1073/pnas.0504437102

Yamniuk, A. P., and Vogel, H. J. (2004). Calmodulin's flexibility allows for promiscuity in its interactions with target proteins and peptides. Mol. Biotechnol. 27, 33-57. doi: 10.1385/MB:27:1:33

Yamniuk, A. P., and Vogel, H. J. (2005). Structural investigation into the differential target enzyme regulation displayed by plant calmodulin isoforms. Biochemistry 44, 3101-3111. doi: 10.1021/bi047770y
Yang, C., Li, A. L., Zhao, Y. L., Zhang, Z. L., Zhu, Y. F., Tan, X. M., et al. (2011). Overexpression of a wheat CCaMK gene reduces ABA sensitivity of Arabidopsis thaliana during seed germination and seedling growth. Plant Mol. Biol. Rep. 29, 681-692. doi: 10.1007/s11105-010-0275-0

Yang, T., Ali, G. S., Yang, L., Du, L., Reddy, A. S., and Poovaiah, B. W. (2010a). Calcium/calmodulin-regulated receptor-like kinase CRLK1 interacts with MEKK1 in plants. Plant Signal. Behav. 5, 991-994. doi: 10.4161/psb.5.8.12225

Yang, T., Chaudhuri, S., Yang, L., Du, L., and Poovaiah, B. W. (2010b). A calcium/calmodulin-regulated member of the receptor-like kinase family confers cold tolerance in plants. J. Biol. Chem. 285, 7119-7126. doi: 10.1074/jbc.M109.035659

Yang, T., Chaudhuri, S., Yang, L., Chen, Y., and Poovaiah, B. W. (2004). Calcium/Calmodulin Up-regulates a cytoplasmic receptor-like kinase in plants. J. Biol. Chem. 279, 42552-42559. doi: 10.1074/jbc.M402830200

Yang, T., and Poovaiah, B. W. (2000a). An early ethylene up-regulated gene encoding a calmodulin-binding protein involved in plant senescence and death. J. Biol. Chem. 275, 38467-38473. doi: 10.1074/jbc.M003566200

Yang, T. B., and Poovaiah, B. W. (2000b). Molecular and biochemical evidence for the involvement of calcium/calmodulin in auxin action. J. Biol. Chem. 275, 3137-3143. doi: 10.1074/jbc.275.5.3137

Yang, T., and Poovaiah, B. W. (2002a). A calmodulin-binding/CGCG box DNAbinding protein family involved in multiple signaling pathways in plants. J. Biol. Chem. 277, 45049-45058. doi: 10.1074/jbc.M207941200

Yang, T., and Poovaiah, B. W. (2002b). Hydrogen peroxide homeostasis: activation of plant catalase by calcium/calmodulin. Proc. Natl. Acad. Sci. U.S.A. 99, 4097-4102. doi: 10.1073/pnas.052564899

Yang, T., and Poovaiah, B. W. (2003). Calcium/calmodulin-mediated signal network in plants. Trends Plant Sci. 8, 505-512. doi: 10.1016/j.tplants.2003.09.004

Yoo, C. Y., Pence, H. E., Jin, J. B., Miura, K., Gosney, M. J., Hasegawa, P. M., et al. (2010). The Arabidopsis GTL1 transcription factor regulates water use efficiency and drought tolerance by modulating stomatal density via transrepression of SDD1. Plant Cell 22, 4128-4141. doi: 10.1105/tpc.110.078691

Yoo, J. H., Park, C. Y., Kim, J. C., Do Heo, W., Cheong, M. S., Park, H. C., et al. (2005). Direct interaction of a divergent CaM isoform and the transcription factor, MYB2, enhances salt tolerance in Arabidopsis. J. Biol. Chem. 280, 36973706. doi: $10.1074 /$ jbc.M408237200

Yoshida, T., Fujita, Y., Sayama, H., Kidokoro, S., Maruyama, K., Mizoi, J., et al. (2010). AREB1, AREB2, and ABF3 are master transcription factors that cooperatively regulate ABRE-dependent ABA signaling involved in drought stress tolerance and require ABA for full activation. Plant J. 61, 672-685. doi: 10.1111/j.1365-313X.2009.04092.x

Zhang, W., Zhou, R.-G., Gao, Y.-J., Zheng, S.-Z., Xu, P., Zhang, S.-Q., et al. (2009). Molecular and genetic evidence for the key role of AtCaM3 in heatshock signal transduction in Arabidopsis. Plant Physiol. 149, 1773-1784. doi: 10.1104/pp.108.133744

Zhang, Y., Xu, S., Ding, P., Wang, D., Cheng, Y. T., He, J., et al. (2010). Control of salicylic acid synthesis and systemic acquired resistance by two members of a plant-specific family of transcription factors. Proc. Natl. Acad. Sci. U.S.A. 107, 18220-18225. doi: 10.1073/pnas.1005225107

Zhou, Y. P., Duan, J., Fujibe, T., Yamamoto, K. T., and Tian, C. E. (2012). AtIQM1, a novel calmodulin-binding protein, is involved in stomatal movement in Arabidopsis. Plant Mol. Biol. 79, 333-346. doi: 10.1007/s11103-012-9915-0

Zhu, J. K. (2001). Cell signaling under salt, water and cold stresses. Curr. Opin. Plant Biol. 4, 401-406. doi: 10.1016/S1369-5266(00)00192-8

Zhu, J. K. (2002). Salt and drought stress signal transduction in plants. Annu. Rev. Plant Biol. 53, 247-273. doi: 10.1146/annurev.arplant.53.091401.143329

Conflict of Interest Statement: The authors declare that the research was conducted in the absence of any commercial or financial relationships that could be construed as a potential conflict of interest.

Copyright $\odot 2015$ Zeng, Xu, Singh, Wang, Du and Poovaiah. This is an open-access article distributed under the terms of the Creative Commons Attribution License (CC BY). The use, distribution or reproduction in other forums is permitted, provided the original author(s) or licensor are credited and that the original publication in this journal is cited, in accordance with accepted academic practice. No use, distribution or reproduction is permitted which does not comply with these terms. 